\title{
Could a Possible Crosstalk between AMPK and TGF- $\beta$ Signaling Pathways Be a Key Player in Benign and Malignant Salivary Gland Tumors?
}

\author{
Nastaran M. Ghahharia Hamed M. Ghahhari ${ }^{\mathrm{b}}$ Mehdi Kadivar $^{\mathrm{a}}$ \\ aDepartment of Biochemistry, Pasteur Institute of Iran, Tehran, \\ bepartment of Otorhinolaryngology and Head and Neck Surgery, Imam Reza Hospital, Tabriz University of Medical Sciences, Tabriz, Iran
}

\section{Keywords}

Salivary gland neoplasms - LKB1 - SMAD4 .

Gene expression profiling

\section{Summary}

Background: Salivary gland tumors (SGTs) are known for their specific heterogeneity and ambiguous outcome for the affected patients. The $L K B 1$ and SMAD4 genes are pivotal components of important signaling pathways, including AMPK and TGF- $\beta$. To our knowledge, no study has reported an association between the expression levels of these genes in SGTs. The expression levels of $L K B 1$ and SMAD4 were evaluated to clarify their possible crosstalk in SGTs. Materials and Methods: A total of 50 fresh tissue specimens were obtained from patients with SGTs, including pleomorphic adenoma (PA), Warthin's tumor (WT), intermediate grade mucoepidermoid carcinoma (MEC), salivary duct carcinoma (SDC), and carcinoma ex pleomorphic adenoma (CexPA), as well as 8 normal samples. Quantitative real-time polymerase chain reaction was performed for all samples with specific primers. Results: Data were analyzed using statistical methods. PA, WT, MEC, and SDC showed a significant decrease in $\angle K B 1$ levels, but the gene was upregulated in CexPA. SMAD4 was overexpressed in all samples. Conclusion: The results suggest a possible link between downregulation of $L K B 1$ and overexpression of $S M A D 4$ in SGTs. $L K B 1$ depletion leads to upregulation of $S M A D 4$, promoting epithelial-mesenchymal transition in tumor cells. Therefore, $L K B 1$ and SMAD4 could be key players in inducing tumor heterogeneity in SGTs.

\author{
Schlüsselwörter \\ Speicheldrüsenneoplasien · LKB1 - SMAD4 . \\ Genexpressionsprofiling
}

\section{Zusammenfassung}

Hintergrund: Speicheldrüsentumoren (SDTs) sind für ihre spezifische Heterogenität sowie ein ungewisses Outcome der betroffenen Patienten bekannt. Die Gene $L K B 1$ und SMAD4 sind ausschlaggebende Komponenten wichtiger Signalwege, einschließlich AMPK und TGF- $\beta$. Unseres Wissens liegen aktuell keine Studien vor, die von einer Assoziation zwischen den Expressionsspiegeln dieser Gene bei SDTs berichten. Wir haben die Expressionsspiegel von $L K B 1$ und SMAD4 evaluiert, um die Möglichkeit eines Crosstalks bei SDTs abzuklären. Material und Methoden: Insgesamt wurden 50 frische Gewebeproben von Patienten mit SDTs einschließlich pleomorphischer Adenome (PA), Warthin-Tumoren (WT), mukoepidermoider Karzinome (MEC; intermediate grade), Speichelgangkarzinome (SGK) und CexPA-Karzinome (carcinoma ex pleomorphic adenoma) sowie 8 normale Proben gewonnen. Mit allen Proben wurde eine quantitative RealTime-Polymerasekettenreaktion mit spezifischen Primern durchgeführt. Ergebnisse: Die erhobenen Daten wurden statistisch analysiert. PA, WT, MEC und SGK zeigten einen signifikant verminderten LKB1-Spiegel, während das Gen in CexPA-Proben hochreguliert war. SMAD4 war in allen Proben überexprimiert. Schlussfolgerung: Unsere Ergebnisse deuten auf eine mögliche Verbindung zwischen der Downregulierung von $L K B 1$ und der Überexprimierung von SMAD4 in SDTs hin. $L K B 1$-Depletion führt zur Hochregulierung von SMAD4, was die epithelial-mesenchymale Transition in Tumorzellen begünstigt. $L K B 1$ und $S M A D 4$ könnten demnach eine Schlüsselrolle bei der Induktion der Tumorheterogenität bei SDTs spielen.

\section{KARGER \\ Fax +497614520714 \\ Information@Karger.de}

www.karger.com (c) 2012 S. Karger GmbH, Freiburg

0378-584X/12/3512-0770\$38.00/0

Accessible online at:

www.karger.com/onk
Mehdi Kadivar, M.Sc., Ph.D.

Department of Biochemistry

Pasteur Institute of Iran

No. 69, Pasteur Ave, Tehran-13164, Iran

kadivar@pasteur.ac.ir 


\section{Introduction}

Salivary gland tumors (SGTs) are rare tumors characterized by various histopathological features and a guarded prognosis. Regrettably, very few studies have reported fundamental molecular mechanisms concerning their development [1]. SGTs comprise nearly $10 \%$ of the neoplasms thought to be originated in the head and neck region. They include benign and malignant tumors, with benign tumors constituting most of the SGTs and malignant forms being less common. The most prevalent type of SGTs is pleomorphic adenoma (PA). PAs grow slowly and, if left untreated, will proliferate [2]. Warthin's tumor (WT) is the second most common type of benign SGTs. A frequent feature is myoepithelial cell differentiation [3, 4]. Among the malignant SGTs, the most frequent type is mucoepidermoid carcinoma (MEC) [5]. Its common characteristic is myoepithelial cell differentiation, and metastasis is a frequent event in its progression [6]. Salivary duct carcinoma (SDC) is an infrequent aggressive tumor with little peer reviewed literature about its molecular foundations [7]. Carcinoma ex pleomorphic adenoma (CexPA) is one of the most frequent malignant mixed SGTs, arising from PA. These tumors occasionally show an invasive behavior [8]. Despite many attempts to ameliorate prognosis and find new treatment methods for patients suffering from SGTs, only little progress has been made in the last 30 years. More studies are needed to find new prognostic approaches and treatment methods. For the investigation of new parameters and markers aimed at new drug development, gene

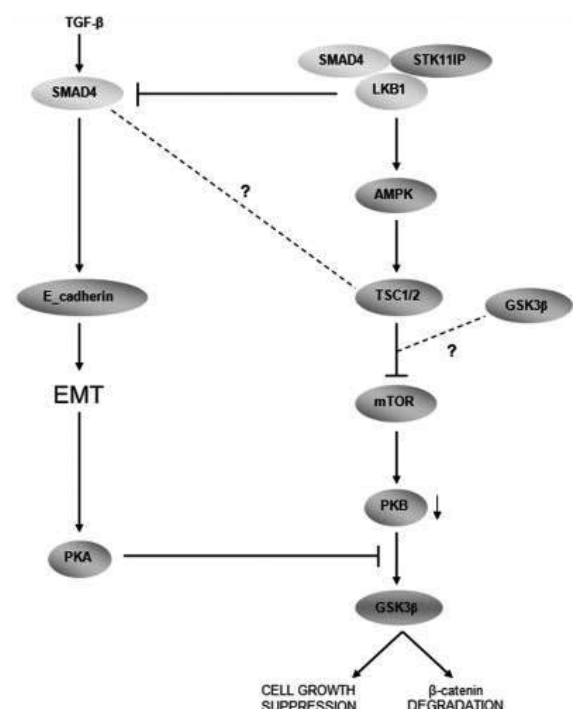

Fig. 1. AMPK and TGF- $\beta$ signaling pathways show a possible crosstalk. $L K B 1$ inhibits mTOR signaling through activating AMPK. $L K B 1$ suppresses $S M A D 4$ to prevent epithelial-mesenchymal transition (EMT) and malignant transformation. SMAD4 increases PKA which can suppress GSK3 $\beta$ activation. This may lead to $\beta$-catenin accumulation in the nuclei, inducing cell proliferation. expression analysis should be included as a useful strategy to unveil the pathological mechanisms surrounding these tumors [1]. The LKB1/AMP-activated protein kinase (AMPK) signaling pathway participates in cell growth and polarity. A strong involvement of this pathway has been reported in a variety of tumors $[9,10]$. SMAD4 plays an integral role in transforming growth factor beta (TGF- $\beta$ ) signal transduction, and its inactivation has been reported in tumors [11, 12]. TGF- $\beta$ also participates in epithelial-mesenchymal transition (EMT) and the metastatic process in tumors. EMT involves generation of tumor stem cells (TSCs) which are considered to be a possible cause of intratumor heterogeneity - a common characteristic of many human tumors such as SGTs. TGF- $\beta$ stimulates EMT through activation of different intrinsic pathways, e.g. AKT, SMAD, and $\beta$-catenin [13]. This study aims to determine a possible association between 2 components of pivotal signaling pathways in SGTs including AMPK and TGF- $\beta$. Recently, $L K B 1$ has been demonstrated to be a negative regulator of TGF- $\beta$ signaling, which represses EMT through the suppression of SMAD4 [14]. LKB1 prevents $S M A D 4$ from being expressed to stop EMT and tumor heterogeneity. Assuming that LKB1 downregulation and SMAD4 overexpression trigger EMT and tumor heterogeneity, a possible crosstalk between AMPK and TGF- $\beta$ signaling pathways could be proposed in SGTs (fig. 1).

\section{Materials and Methods}

\section{Patients and Tissue Sampling}

A total of 50 fresh tissue specimens were obtained from surgically resected salivary gland tissues, including PA $(\mathrm{n}=12)$, WT $(\mathrm{n}=7)$, intermediate grade MEC $(\mathrm{n}=9)$, SDC $(\mathrm{n}=7)$, and CexPA $(\mathrm{n}=7) .8$ histologically normal tissue samples were obtained as controls from unaffected areas of the salivary glands of patients with PA. All samples were examined by an experienced pathologist to ensure their histomorphological credibility. $1-\mathrm{cm}^{2}$ sections, each 5 microns in thickness, from fresh frozen tissues were analyzed for confirmatory pathology and to determine the percentage of tumor cells at each site. For all samples, at least $50 \%$ of the total cells analyzed were tumor cells. All patients gave informed consent, and the study was approved by the ethical committee of the Pasteur Institute of Iran. According to the medical records of the study subjects, which were obtained for detailed information on potential risk factors influencing SGTs behavior, none of the patients had undergone radiotherapy or chemotherapy before tissue collection. Tissues were kept in RNA Later reagent (QIAGEN, Hilden, Germany) and then stored at $-80{ }^{\circ} \mathrm{C}$ until RNA extraction.

RNA Isolation, cDNA Synthesis, and Primer Design

A total of $50 \mathrm{mg}$ of each tissue sample were homogenized using $\mathrm{RNX}^{\mathrm{TM}}$ Plus reagent (CinnaGen, Tehran, Iran). RNA was extracted according to

Table 1. Primers used in real-time assay

\begin{tabular}{lll}
\hline Genes & Forward primer & Reverse primer \\
\hline LKB1 & GGGTCACCCTCTACAACATCACC & GTACTCAAGCATCCCTTTCAGCAG \\
SMAD4 & ACAAGTCAGCCTGCCAGTATACT & GGTGGTAGTGCTGTTATGATGGTAAG \\
RNpol $I I$ & GCTGGTTTTGGTGACGACTTG & TCTTCCTCCTCTTGCATCTTGTTC \\
\hline$L K B 1=$ Liver kinase B $1 ; S M A D 4=$ SMAD family member 4; $R N p o l ~ I I=$ RNA polymerase II. & \\
\hline
\end{tabular}


the manufacturer's instructions. For cDNA synthesis, optical density and concentration were measured using a NanoPhotometer ${ }^{\circledast}$ (Implen, Munich, Germany) at 260 and $280 \mathrm{~nm}$. Definite amounts of each RNA sample were utilized to generate cDNA in separate tubes. Oligo (d)Ts were added as primer in a total volume of $20 \mu \mathrm{l}$. Thermal cycle conditions were as following: $25^{\circ} \mathrm{C}$ for $30 \mathrm{~s}, 45^{\circ} \mathrm{C}$ for $4 \mathrm{~min}, 55^{\circ} \mathrm{C}$ for $30 \mathrm{~s}$ for 12 repeat cycles, and then $95^{\circ} \mathrm{C}$ for $5 \mathrm{~min}$ for enzyme inactivation. Sequences of all primers for quantitative reverse transcription polymerase chain reaction (qRT-PCR) were designed utilizing Primer Express Software version 3.0 (Applied Biosystems, Foster City, CA, USA). To avoid any remarkable homology with other genomic sequences, primers were subjected to a comprehensive search in the NCBI/BLAST databases. Detailed information regarding the primers is given in table 1.

\section{Quantitative Real-Time RT-PCR and Data Analysis}

Real-time qRT-PCR for the genes of interest was conducted for every sample in a total volume of $20 \mu \mathrm{l}$, including $10 \mu \mathrm{l}$ SYBR Green II Master Mix (Takara Bio Inc., Shiga, Japan), $1.2 \mu \mathrm{l}$ of mixed primer (forward and reverse), $4.8 \mu \mathrm{l}$ of cDNA, and $4 \mu \mathrm{l}$ of double-distilled water $\left(\mathrm{ddH}_{2} \mathrm{O}\right)$. RNA polymerase II (RNpol II) was selected as an endogenous control gene for the assays. Real-time PCR amplifications was performed in triplicate using the Rotor Gene 6000 (Corbett, Sydney, Australia) and two-step cycling: $95{ }^{\circ} \mathrm{C}$ for $5 \mathrm{~s}$ and $60{ }^{\circ} \mathrm{C}$ for $10 \mathrm{~s}$, repeating 40 cycles. To calculate the PCR efficiency of each target and reference gene, serial dilutions of 1 normal tissue cDNA were prepared, and the reaction was performed for each gene in separate tubes. For drawing standard curves, serially diluted normal cDNA was adapted to concentrations of 1,000 , 100,10 , and $1 \mathrm{ng}$ cDNA for each reaction. In order to check the specifi-

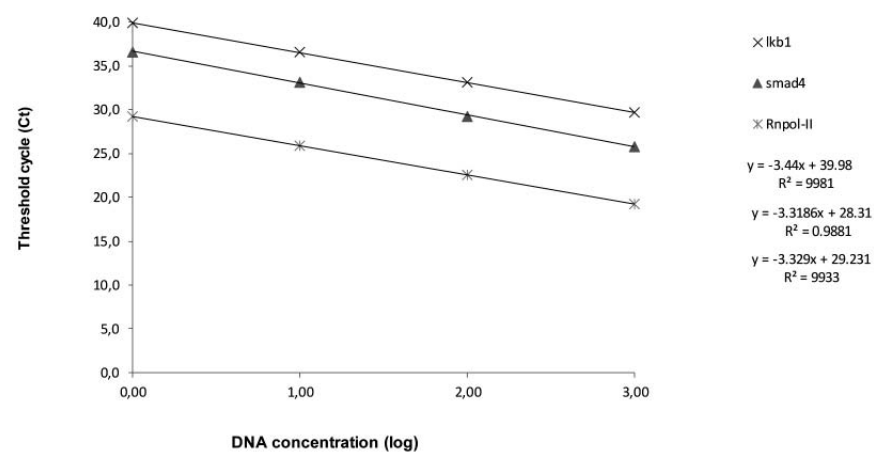

Fig. 2. Optimization of real-time PCR assays for analyzing target genes. Standard curves designed by plotting $\Delta \mathrm{CT}$ parameters of each target gene against the amount of serially diluted template DNA per reaction. Plots showed an R2 > 0.99 with $98 \%$ efficiency of the PCR reaction, with a slope of -3.4 (NR = Normal; PA = pleomorphic adenoma; WT = Warthin's tumor; $\mathrm{MEC}=$ intermediate grade mucoepidermoid carcinoma; $\mathrm{SDC}=$ salivary duct carcinoma; $\mathrm{CexPA}=$ carcinoma ex pleomorphic adenoma). city of the reaction and sensitivity of SYBR Green II, a melting curve analysis was performed (fig. 2). In addition, validation of 3 different reference genes including RNpol II, TATA-binding protein (TBP), and $\beta$-actin was performed to select the best endogenous control gene for the assays. Although $\beta$-actin is used as a popular reference gene in most studies about SGTs, large variations in its expression level were found. Subsequently, RNpol II was recognized as the most appropriate reference gene, having the least amount of alterations in its expression level in various samples. We suggest this gene as a suitable endogenous control in studies evaluating gene expression level in SGTs (fig. 4; gel image in the supplementary data). To quantify analytical data, the comparative $\Delta \mathrm{Ct}$ method was used by applying the following formula:

$$
\begin{aligned}
& 2^{-\triangle \triangle C T} \text {, where }
\end{aligned}
$$

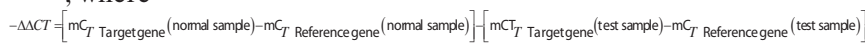

Mean gene expression and the related standard error of the mean (SEM) were compared in normal and SGT samples. One-way ANOVA with Dunnett's post-hoc test was performed using GraphPad InStat version 3.05 software (GraphPad Software, San Diego, CA, USA). A p value of $<0.05$ was considered significant.

\section{Results}

\section{Real-Time PCR Optimization}

The optimum primer concentration was measured. To correlate quantization analysis with gene expression, PCR efficiencies for targets and reference genes were calculated by standard curve plotting. All best-fit trend lines were within the accepted range $(-3.6<$ slope $<-3.1)$ (fig. 1$)$. The dynamic range of template cDNA concentrations was measured between 1 and 1,000 ng by plotting $\Delta \mathrm{C}_{\mathrm{T}}$ parameters of each gene against the amount of input DNA. In addition, gel electrophoresis analysis of the PCR products revealed a single band for each fragment with the expected amplicon length. All amplification reactions for genes presented a single peak at the required melting temperature $(\mathrm{Tm})$.

\section{Gene Expression Quantification}

Real-time qRT-PCR was performed to investigate whether the mRNA expression levels of the 2 genes of interest was up- or downregulated in SGTs (fig. 3). Values are characterized as mean \pm SEM. One-way ANOVA and Dunnett's multiple comparison tests showed that all results for $L K B 1$ were significant ( $<0.01$ ) (fig. $3 \mathrm{~A}$ ). PA and WT showed very low mRNA expression. MEC and SDC revealed underexpression of the gene among malignant SGTs. CexPA was the only group which showed high levels of gene expression. Interestingly, SMAD4 was upregulated in CexPA by 8 -fold $(\mathrm{p}<0.01)$ as compared with the control group. The gene showed a 2.9-fold increase in MEC $(\mathrm{p}<0.01)$, and was upregulated by at least 2 -fold in SDC specimens $(p<0.01)$ (fig. 3 B). The $p$ values of all groups were less than 0.01 .
Fig. 3. Salivary gland tumor cells express different levels of $L K B 1$ and SMAD4. Data represents the mean ratio of triplicate real-time PCR assays for A $L K B 1$ and B SMAD4 normalized to the expression level of the RNpol II gene $(* * \mathrm{p}<0.01$ as compared with the control group using Dunnett's multiple comparison tests. $\mathrm{NR}=$ Normal; $\mathrm{PA}=$ pleomorphic adenoma; WT $=$ Warthin's tumor; $\mathrm{MEC}=$ mucoepidermoid carcinoma; $\mathrm{SDC}=$ salivary duct carcinoma; CexPA = carcinoma ex pleomorphic adenoma).
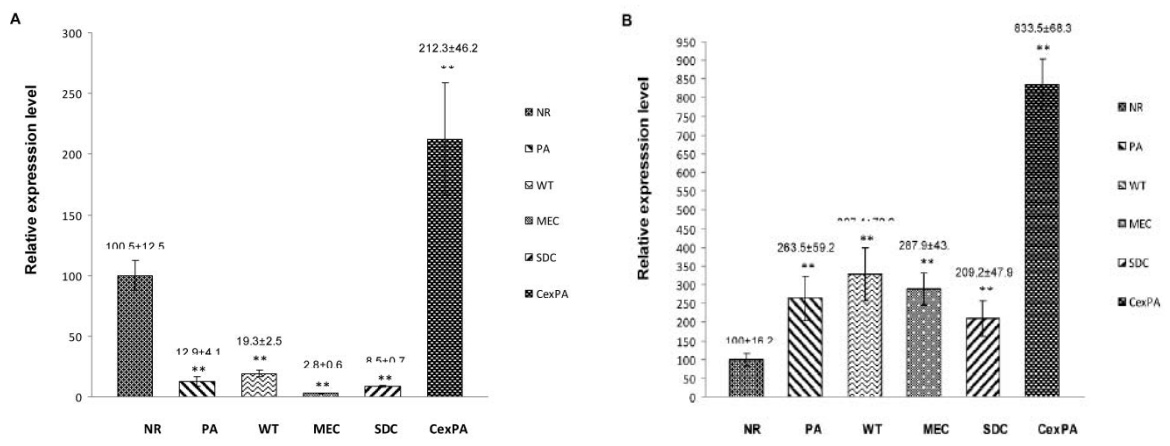


\section{Discussion}

With their heterogeneous histopathology and complications surrounding their morphological characteristics, SGTs require a differentially finalized diagnosis and carry an uncertain prognosis for the affected patients [15]. The aim of this study was to clarify a crosstalk between AMPK and TGF- $\beta$ signaling pathways in benign and malignant SGTs. LKB1 and $S M A D 4$ have been inspected in common human tumors, but their possible crosstalk and involvement in EMT and tumor heterogeneity has not been studied to date $[11,16,17]$. There is no literature to connect $L K B 1$ deficiency with human SGTs, but somatic mutation has been reported to be a current event in human lung cancer, suggesting a tumor-suppressive role in epithelial tissues [18]. Also, the TGF- $\beta$ signaling pathway contains crucial tumorgenesis mediators like SMAD4 which play a role in the initiation and progression of many human tumors and EMT [16, 19]. Its deficiency promotes $\beta$-catenin accumulation and epithelial cell differentiation and proliferation [11]. A pluripotent stem cell group is responsible for the heterogeneity reported within SGTs; however, based on recent data, the histomorphological heterogeneity could also be related to all the mature cell types in salivary gland tissues [20]. When oncogenesis occurs, the level of differentiation of the reserve cell's descendants determines the heterogeneity of the SGTs and their mesenchymal differentiation affecting the results of gene expression assays [21].

Highly sensitive real-time qRT-PCR assays were used to measure the expression levels of the studied genes. $L K B 1$ was significantly decreased in all groups except for CexPA. $S M A D 4$ was overexpressed in all samples. CexPA is a very invasive carcinoma, and overexpression of $L K B 1$ has been proven to play a role in the development of carcinomas $[22$, 23]. SMAD4 overexpression may also be the result of TGF- $\beta$ pathway activation which induces EMT in CexPA [24]. CexPA arises from PA which is a very heterogeneous group of SGTs. Overexpression of E-cadherin in PA and CexPA promotes EMT and heterogeneity $[25,26]$. Although most gene expression profiles are based on crude tumor samples including $<50 \%$ tumor cells and are based on gene expression of the tumor tissue, the high level of SEM in CexPA could be the result of intratumor heterogeneity or different amounts of normal cells in the tumor samples [27].

An interesting relationship between reduction of $L K B 1$ and overexpression of $S M A D 4$ suggests a possible crosstalk between AMPK and TGF- $\beta$ where the reduction of $L K B 1$ leads to increased levels of SMAD4 and EMT. EMT is a common feature of both benign and malignant SGTs, causing the emergence of both epithelial and mesenchymal cells in patho- logical tissue specimens. Activation of SMAD4 suppresses E-cadherin, resulting in reduced contact inhibition and, subsequently, modified morphogenesis in tumors [21, 28]. EMT is related to mechanisms leading to metastasis and TSC generation. TSCs are known to be involved in tumor development and heterogeneity $[13,29]$. The possibility of metastasis and tumor heterogeneity is determined by the type of TSCs from which a tumor develops $[30,31]$. The clonal evolution model expects that genetic heterogeneity among tumor cells leads to heterogeneity in phenotype, function, and response to therapy. Moreover, epigenetic differences give an additional heterogeneity to the tumor colony [32]. Therefore, tumor heterogeneity, EMT, and level of pluripotent stem cell differentiation affect the result. Gene expression analysis of bulk tumor tissue could be restricted by tumor genetic and epigenetic heterogeneity, affecting the overall conclusion [33,34]. At the same time, each gene in different tumors or in the same tumor is expressed in various amounts. This heterogeneous gene expression explains the histopathological heterogeneity found in tumors [34]. All in all, tumor heterogeneity in SGTs caused by EMT could be linked to downregulation of $L K B 1$ and overexpression of SMAD4; both have functions in EMT and tumor metastasis. This study presents a primary understanding of a possible crosstalk between APMK and TGF- $\beta$ signaling pathways in SGTs. Supplementary studies about these genes are required to draw an applicable conclusion about their possible interaction, contributing to EMT and tumor heterogeneity in SGTs.

\section{Acknowledgement}

This project was supported by the Pasteur Institute of Iran (no. 510). The authors would like to thank Dr O. Khodai for preparing the manuscript. We also thank the staff of the Biochemistry Department of the Pasteur Institute of Iran.

\section{Online Supplementary Figure}

Fig. 4. RNA polymerase II ( $R N p o l I I)$ gene gel electrophoresis. $R N p o l ~ I I$ showed no variation in its expression level in different normal and SGT samples. Samples: 1, ladder 100 bp; 2, normal; 3, pleomorphic adenoma; 4, Warthin's tumor; 5, mucoepidermoid carcinoma; 6, carcinoma ex pleomorphic adenoma; 7, salivary duct carcinoma.

To access the figure please refer to $w w w$. karger.com/DOI=000345131.

\section{Disclosure Statement}

The authors declare no conflict of interest. 
1 Maruyama S, Cheng J, et al.: Establishment and characterization of pleomorphic adenoma cel systems: an in-vitro demonstration of carcinomas arising secondarily from adenomas in the salivary gland. BMC Cancer 2009;9:247.

2 Declercq J, Van Dyck F, et al.: Upregulation of Igf and Wnt signalling associated genes in pleomorphic adenomas of the salivary glands in PLAG1 transgenic mice. Int J Oncol 2008;32:1041-7.

3 Stenman G: Fusion oncogenes and tumor type specificity - insights from salivary gland tumors. Semin Cancer Biol 2005;15:224-35.

4 Pastore A, Carinci F, Pelucchi S: Genetic expression profiling of parotid neoplasms by cDNA microarrays. Acta Otorhinolaryngol Ital 2005;25:153-60.

$\checkmark 5$ Yin HF, Okada N, Takagi M: Apoptosis and apoptotic-related factors in mucoepidermoid carcinoma of the oral minor salivary glands. Pathol Int 2000;50:603-9.

6 Rapidis AD, Givalos N, et al.: Mucoepidermoid carcinoma of the salivary glands. Review of the literature and clinicopathological analysis of 18 patients. Oral Oncol 2007;43:130-6.

7 Nagao T, Gaffey TA, et al.: Invasive micropapillary salivary duct carcinoma: a distinct histologic variant with biologic significance. Am J Surg Pathol 2004;28:319-26.

8 Tarakji B, Kujan O, Nassani MZ: Immunohistochemical expression of p53 in pleomorphic adenoma and carcinoma ex pleomorphic adenoma. J Cancer Epidemiol 2010;2010:250606.

$\checkmark 9$ Van Veelen W, Korsse SE, et al.: The long and winding road to rational treatment of cancer associated with LKB1/AMPK/TSC/mTORC1 signaling. Oncogene 2011;30:2289-303.

10 Nakada D, Saunders TL, Morrison SJ: Lkb1 regulates cell cycle and energy metabolism in haematopoietic stem cells. Nature 2010;468:653-8.

11 Li W, Qiao W, et al.: Squamous cell carcinoma and mammary abscess formation through squamous metaplasia in Smad4/Dpc4 conditional knockout mice. Development 2003;130:6143-53.
12 Zhou S, Buckhaults P, et al.: Targeted deletion of Smad4 shows it is required for transforming growth factor beta and activin signaling in colorectal cancer cells. Proc Natl Acad Sci U S A 1998;95:2412-6.

13 Bonde AK, Tischler V, et al.: Intratumoral macrophages contribute to epithelial-mesenchymal transition in solid tumors. BMC Cancer 2012;12:35.

14 Moren A, Raja E, et al.: Negative regulation of TGFbeta signaling by the kinase LKB1 and the scaffolding protein LIP1. J Biol Chem 2011;286: 341-53.

15 Leivo I: Insights into a complex group of neoplastic disease: advances in histopathologic classification and molecular pathology of salivary gland cancer. Acta Oncol 2006;45:662-8.

16 Yang G, Yang X: Smad4-mediated TGF-beta signaling in tumorigenesis. Int J Biol Sci 2010;6:1-8.

17 Conde E, Suarez-Gauthier A, et al.: Specific pattern of LKB1 and phospho-acetyl-CoA carboxylase protein immunostaining in human normal tissues and lung carcinomas. Hum Pathol 2007;38: 1351-60.

18 Ji H, Ramsey MR, et al.: LKB1 modulates lung cancer differentiation and metastasis. Nature 2007; 448:807-10.

19 Miguita L, Martinez EF, et al.: FGF-2, TGFbeta-1, PDGF-A and respective receptors expression in pleomorphic adenoma myoepithelial cells: an in vivo and in vitro study. J Appl Oral Sci 2010;18:83-91.

20 Batsakis JG, Regezi JA, et al.: Histogenesis of salivary gland neoplasms: a postulate with prognostic implications. J Laryngol Otol 1989;103:939-44.

21 Batsakis JG: Salivary gland neoplasia: an outcome of modified morphogenesis and cytodifferentiation. Oral Surg Oral Med Oral Pathol 1980;49:229-32.

22 Shintani S, Alcalde RE, et al.: Extracellular matrices expression in invasion area of adenoid cystic carcinoma of salivary glands. Cancer Lett 1997;116: 9-14.

23 Zhong D, Liu X, et al.: LKB1 is necessary for Aktmediated phosphorylation of proapoptotic proteins. Cancer Res 2008;68:7270-7.
24 Torbenson M, Marinopoulos S, et al.: Smad4 overexpression in hepatocellular carcinoma is strongly associated with transforming growth factor beta II receptor immunolabeling. Hum Pathol 2002;33: 871-6.

25 Prabhu S, Kaveri H, Rekha K: Benign, malignant salivary gland tumors: comparison of immunohistochemical expression of e-cadherin. Oral Oncol 2009;45:594-9.

26 Araujo VC, Demasi AP, et al.: Collagen type I may influence the expression of E-cadherin and betacatenin in carcinoma ex-pleomorphic adenoma. Appl Immunohistochem Mol Morphol 2009;17: 312-8.

27 Roepman P, Schuurman A, et al.: A gene expression profile for detection of sufficient tumour cells in breast tumour tissue: microarray diagnosis eligibility. BMC Med Genomics 2009;2:52.

28 Aigner T, Neureiter D, et al.: Epithelial-mesenchymal transdifferentiation and extracellular matrix gene expression in pleomorphic adenomas of the parotid salivary gland. J Pathol 1998;186:178-85.

29 Grunewald TG, Herbst SM, et al.: Understanding tumor heterogeneity as functional compartments superorganisms revisited. J Transl Med 2011;9:79.

30 Tu SM, Lin SH, Logothetis CJ: Stem-cell origin of metastasis and heterogeneity in solid tumours. Lancet Oncol 2002;3:508-13.

31 Bonavia R, Inda MM, et al.: Heterogeneity maintenance in glioblastoma: a social network. Cancer Res 2011;71:4055-60.

32 Shackleton M, Quintana E, et al.: Heterogeneity in cancer: cancer stem cells versus clonal evolution. Cell 2009;138:822-9.

33 Marusyk A, Almendro V, Polyak K: Intra-tumour heterogeneity: a looking glass for cancer? Nat Rev Cancer 2012;12:323-34.

34 Khoshnoud R, He Q, et al.: The impact of RNA standardization and heterogeneous gene expression on the results of cDNA array of human breast carcinoma. Int J Mol Med 2010;25:735-41. 